\title{
DISTRIBUIÇÃO DAS ATIVIDADES TERCIÁRIAS NO BRASIL
}

\author{
Luís Henrique Freitas Diniz \\ Ricardo Alexandrino Garcia \\ Ralfo Edmundo da Silva Matos`
}

\section{Resumo}

O presente trabalho busca caracterizar a rede de atividades terciárias brasileira, inserindo-a na discussão relativa à reestruturação econômica do último quartel do século XX, bem como ao movimento de crescente integração social em escala mundial. No cerne desses processos está o desenvolvimento de novas tecnologias, sobretudo nas áreas de transportes e telecomunicações promovendo uma mudança na própria relação espaço-tempo, favorecendo o que Milton Santos (1993) chamou "territórios-rede". Essa reestruturação do território possibilita a desconcentração de uma série de atividades, sobretudo aquelas relacionadas mais diretamente a funções produtivas. Por outro lado, uma série de outras atividades demonstra um movimento de concentração, sobretudo em ambientes metropolitanos, estas relacionadas, sobretudo, à gestão do território e à articulação local-global, de importância crescente. Esse processo aponta para a crescente separação das funções produtivas, desconcentradas, das funções de gestão e difusão de informação e conhecimento, em crescente concentração. Nesse contexto, o setor terciário ganha grande importância na dinâmica territorial da economia, sobretudo dando base às articulações espaciais sejam elas locais, globais, ou local-globais. Essa nova organização tem impactos definitivos sobre a organização e distribuição da população, do mercado de trabalho, com ênfase a aspectos qualitativos, denotando a crescente seletividade de certos espaços. No caso brasileiro, esse processo traz impactos importantes, com a expansão, bem como ganho de musculatura, da rede terciária brasileira como um todo. Mas, sobretudo, para um movimento de concentração de certas atividades de maior nível de produtividade e renda, assim como conteúdo técnico em localidades centrais, tal como busca explicitar esse trabalho.

\footnotetext{
•Dr. Prof. Departamento de Geografia/UFMG; alexandrinogarcia@gmail.com

`Dr. Prof. Departamento de Geografia/UFMG; ralfomatos@yahoo.com.br 


\section{1- O SETOR DE SERVIÇOS E A REESTRUTURAÇÃO ECONÔMICA}

O Setor terciário se caracteriza por ser um setor de difícil conceituação. Isso sedeve em grande medida por sua alta heterogeneidade. Essa dificuldade é enfrentada pela construção de tipologias, que ao classificar as atividades terciárias dentro de parâmetros variados, possibilita a formação de grupos com maior grau de homogeneidade.

As tipologias mais comuns são variações da tipologia proposta por Brownin eSingelman (1978), que distingue os serviços por tipos de demanda, classificando os serviços entre serviços produtivos, serviços distributivos, serviços pessoais e serviços sociais. Essas classificações se mostram importantes à medida que possibilitam vislumbrar tendências discrepantes dentro dessas atividades, tal como veremos mais adiante.

O processo de "terciarização", para o qual chamamos a atenção anteriormente,enquanto processo de crescimento da importância do setor terciário na dinâmica econômica como um todo, incitou importantes discussões a respeito do caráter desse processo e de sua relação com a dinâmica econômica como um todo.

Uma delas foi a corrente pós-industrialista, derivada dos estudos de Fisher(1952) e Clark (1960). Esta propunha o desenvolvimento econômico em etapas, partindo da agricultura, à industria e por fim os serviços.

$\mathrm{Na}$ concepção pós-industrialista o desenvolvimento do setor de serviços era fruto da constituição de uma "sociedade de consumo de massa", atrelando esse desenvolvimento aos serviços finais. O crescimento do setor de serviços seria resultadode uma alta elasticidade-renda de sua demanda, segundo a "lei de Engel", pela qual em etapas avançadas de desenvolvimento econômico a demanda por serviços seria maior do que a por bens manufaturados. Este fator aliado ao gap de produtividade entre o setor de serviços e o setor industrial, resultaria na transferência de mão-de-obra para o setor terciário.

$\mathrm{O}$ argumento pós-industrialista acaba por se mostrar falho, à medida que o próprio diferencial de produtividade, ponto central em sua tese, levaria a um aumento relativo dos preços destes serviços no médio e longo prazo. Isso teria impactos negativos sobre este setor, sobretudo levando em conta sua alta elasticidade-renda da demanda.

Além disso, o argumento pós-industrialista não dava conta das verdadeiras transformações que estavam ocorrendo, não de um novo paradigma econômico centrado nas atividades terciárias, mas sim de uma reestruturação da indústria, com ganho de importância do setor terciário na divisão espacial do trabalho, sobretudo de forma auxiliar à produção. 
Outra visão importante para o entendimento do setor terciário, sobretudo em países de industrialização tardia, caso do Brasil, é a visão da escola estruturalista latino americana, a escola cepalina. Segundo essa visão, o alargamento da participação do setor terciário, sobretudo na estrutura do emprego, deve-se em grande medida a sua funcionalidade enquanto absorvedor de mão-de-obra, principalmente aquela de baixaqualificação.

Apesar da visão cepalina ser bastante datada, refletindo em grande medida o processo de êxodo rural e elevado crescimento demográfico, decorrentes do processo de industrialização e urbanização tardios, típicos de um passado recente latino-americano. Dessa forma, ela nos chama a atenção a uma importante funcionalidade de setor terciário, sua capacidade de acomodação da mão-de-obra excedente.

Dessa forma faz-se necessário distinguir duas dinâmicas na expansão do setorterciário: a primeira ligada ao processo de modernização e reestruturação da indústria, beneficiando-se de seus transbordamentos tecnológicos e com níveis de produtividade maiores que a média dos serviços em geral; a segunda com um importante papel na acomodação da mão-de-obra excluída desse núcleo dinâmico da economia, com funções de baixa produtividade, explicando em grande medida o diferencial de produtividade entre indústria e serviços vistos agregadamente.

O setor terciário guarda importante relação com o processo de urbanização, sobretudo no contexto do processo de industrialização, em que este necessitava da formação de um complexo de serviços capazes de fornecer os insumos básicos à reprodução da força de trabalho, ao mesmo tempo em que sua formação concentrada fornecia escala para a indústria em termos de mercado. Para entender esta ideia deve-se partir de uma característica fundamental do setor terciário que é sua relativa intransportabilidade, o que determina sua restrição espacial. Essa restrição espacial faz com que as atividades terciárias se localizem em localidades relativamente centrais, de acordo com as escalas de demanda necessárias a cada atividade especificamente, e com a estrutura de incentivos relacionada aos aspectos aglomerativos e desaglomerativos.

As primeiras tentativas de entender a lógica de localização de atividades econômicas já estão implícitas nas obras de Von Thünen ([1826], 1966), Haig (1920), Lösch (1910), em que desenvolve-se um raciocínio em que atividades mais intensivas do ponto de vista do fator terra localizem-se em regiões centrais, enquanto que atividades que se utilizam do fator terra de forma mais extensiva localizem-se em regiões periféricas.

As atividades terciárias, em geral têm um uso mais intensivo do solo, o que combinado a seu caráter de restrição espacial, dado por sua intransportabilidade, e sua dependência de outras atividades complementares, caracterizam as atividades terciárias enquanto relativamente concentradas e centralizadas. Seguindo este caminho, chegamos a uma distribuição espacial tal qual a proposta por 
Christaller (1933), com a estruturação de uma rede de localidades centrais, de acordo com as escalas de oferta de serviços (estas em função da estrutura de demanda), com os centros hierarquicamente superiores ofertando serviços a suas regiões dependentes.

O modelo de Christalleriano se mostra primordial ao introduzir a concepção de rede de cidades, concepção amplamente utilizada ainda hoje para o entendimento da distribuição das cidades no território. Nessa concepção a função primordial da centralidade é centralizar a oferta de serviços a suas regiões complementares. O crescimento destas centralidades leva a um aumento mais do que proporcional da demanda de bens e serviços, bem como da renda líquida recebida pelos seus habitantes.O que aumenta o seu potencial enquanto centro consumidor e consequentemente diversifica a sua oferta de bens e serviços e realimenta a dependência das regiões complementares.

Nos países subdesenvolvidos ou em desenvolvimento, caso do Brasil, o processo de urbanização e industrialização tardios fez com que o processo de "terciarização", estivesse por muito tempo quase que exclusivamente relacionado a sua funcionalidade como absorvedor de mão-de-obra excedente, de forma que só a partir das décadas de 60 e 70 é que se fez sentir os efeitos da reestruturação das relações inter-setoriais, em que as atividades terciárias passam a ter importância crescente no núcleo dinâmico da economia. Nesta dinâmica a expansão das atividades terciárias passa a refletir o próprio crescimento da divisão social do trabalho em um novo paradigma de bases estritamente científicas. Daí a consolidação de centros urbanos capazes de oferecer serviços avançados passa a ser um requisito ao processo de industrialização, destacando o papel indutor de desenvolvimento deste setor.

Esses espaços passam a representar pólos de absorção de mão-de-obra altamente qualificada, e polivalente, adaptada ao padrão cada vez mais flexível da organização produtiva, sobretudo em suas funções terciárias. O desenvolvimento dos serviços, sobretudo aqueles ligados à eficiência dos transportes, à telecomunicação e à transmissão de dados, permite o desenraizamento e a relativa desconcentração de uma série de atividades, principalmente aquelas com baixo grau relativo de capital fixo, relativamente independentes de mão-de-obra especializada, e dependentes de insumos. Por outro lado, atividades produtivas-chave, de maior conteúdo técnico-científico sugerem um movimento de concentração em territórios centrais, porém cada vez mais inseridas em redes de relacionamentos que vão além de suas regiões propriamente ditas, até mesmo a células desterritorializadas de seus sistemas de produção e marketing.

Tanto as atividades territorializadas, como as desterritorializadas, dão origem a sistemas de produção de localização globalizada, dando origem ao termo "glocalizado", sendo que é através das atividades centrais que se dão as articulações local-globais, mecanismo chave nesse sistema, essenciais à própria desconcentração das demais atividades. Assim, o processo de centralização dessas atividades 
obedece a algumas forças causais: a)economias de aglomeração; b)excedentes e interdependências organizacionais, desenvolvidas em contextos locais específicos que condicionam o aprendizado tecnológico, envolvendo ações partilhadas e transferência de conhecimento tácito.

O desenvolvimento tecnológico se dá em localizações-base, em um ambiente de produção territorialmente concentrado, com centros de pesquisa e desenvolvimento emão-de-obra qualificada. Esses distritos tecnológicos, responsáveis pelas articulações local-globais, funcionam como nodos de uma rede transfronteiriça (RTF), capaz de expandir e integrar uma série de empresas formadas e operando em rede (MATTOS, 2004). Este processo permite a formação de um espaço mundial de acumulação, onde empresas-rede valorizam seu capital em uma série de atividades e territórios.

A RTF se expande em direção a cidades de características metropolitanas, lócus por excelência das relações sociais e econômicas (PANIZZI, 1990). Surgem novascidades com estas características, em uma dinâmica de "desconcentração concentrada", dando maior musculatura à rede. Esses centros passam, de fato, a ofertar uma série de serviços produtivos avançados. O que permite a difusão de tecnologias de todos os tipos, desde a implantação de novos processos de produção, até formas de capitalização ou articulação institucional, favorecendo a "gestão do território" e, por consequência, maior produtividade e valorização do capital.

A crescente integração das relações sociais em rede, relações ora verticais, ora horizontais, aumenta de sobremaneira a complexidade dessas relações, e como tal o nível de incerteza relacionada ao sistema como um todo. Daí a razão pela qual à medida que a tecnologia permite a dispersão espacial dessas relações requer uma gestão espacial altamente centralizada, evocando a figura dos centros decisórios, espaços de irradiação político-tecnológica, produtoras mais do que de bens, mas de idéias. Delas emergem bases para fluxos informacionais que sejam ao mesmo tempo universalistas e adaptáveis a diferentes particularidades.

Nesse contexto é que se desenvolvem o que Dreifuss (2004) nomeou tecnobergs, grandes corporações multinacionais estruturadas a partir de uma gama infindável de encadeamentos, seja a montante ou a jusante, de arranjos produtivo-espaciais mutidimensionais, referenciados a uma divisão técnico-espacial do trabalho em escala global, de forma que a corporação em si é apenas a "ponta de um iceberg" de estruturas de produção e distribuição gigantescas. Tecnobergs centram suas atividades na viabilização da produção de matrizes tecnológicas (a tecnologia de ponta) a partir das quais se desenvolvem uma série de outras inovações e adaptações multifuncionais a serem disseminadas multisetorialmente o que lhe garante um mercado extenso e diversificado

A produção destas matrizes envolve investimentos altíssimos, sobretudo em mão-de-obra qualificada e equipamentos de alta complexidade. Estes investimentos concentram-se, principalmente, na fase de desenvolvimento, de forma que são em grande medida custos fixos, dando-lhe ganhos de 
escala crescente, e determinando uma estrutura de mercado concentrada. Além disso, o alto nível de financiamento exigido por estas atividades, bem como a incerteza envolvida, restringem seu funcionamento a regiões com alta disponibilidade de capital.

Inserida nessa teia de relações, cada ação de cada agente ganha um alto grau de conteúdo informacional, permitindo a "recalibragem" constante e adequação dos sistemas, pelo monitoramento em tempo real, via fluxo informacional. A crescente complexidade dessas relações, e o caráter específico da produção tecnológica, se reflete no ganho de importância das relações interinstitucionais, e consequentemente no desenvolvimento de novas formas de interface institucional. Isso porque o alto grau de incerteza envolvido na produção tecnológica de ponta exige uma estrutura de mercado que seja cooperativa e articulada entre as diversas instituições, já que envolve uma gama imensa de atividades, cada uma com demandas tecnológicas distintas, o que exige matrizes tecnológicas versáteis e flexíveis. No que ganha força o que Storper (1997) chama de "ativos relacionais", que dependem de uma série elementos sociais locais. Adivisão técnico-política do território torna-se cada vez mais seletiva no processo de produção do espaço, sobretudo com relação às qualidades societárias.

Nessa nova divisão as regiões de maior centralidade se especializam enquanto pólos indutores de conhecimento e inovação, surgem novos pólos técnico-produtivos, responsáveis por traduzir as matrizes tecnológicas em produtos "georreferenciados", ou seja adaptados ao contexto local/regional. Configura-se, assim, uma divisão técnico espacialdas atividades, referenciada a uma nova divisão técnica do trabalho, não mais intra-fabril, mas cotejada por arranjos espaciais específicos.

Por fim, o setor terciário passa a ter funcionalidades importantes na configuração territorial, seja na expansão da rede urbana, que induz e é induzida pela expansão de uma série de "serviços urbanos", seja pelo próprio caráter das estruturas produtivas em uma economia centrada na inovação.

\section{2 - SETOR TERCIÁRIO, TIPOLOGIAS, VERTICALIDADES E FUNCIONALIDADES ESPACIAIS}

O setor terciário, analisado segundo sua estrutura interna, reflete em grandemedida o duplo movimento de dispersão da rede urbana e da cultura urbano-industrial. A centralização da gestão da produção aumentou sobremaneira a complexidade das relações em que se inserem estas atividades, adequando-as a cada contexto e escala de funcionamento das atividades produtivas, conectando-as aos diversos espaços de fluxos, com tudo que isso envolve.

A dispersão da rede urbana reflete na expansão dos serviços ligados às funçõesde infraestrutura e reprodução urbana, atividades tais como serviços públicos básicos, como coleta de lixo, transportes urbanos e interurbanos, serviços de saúde e educação, comércio, serviços de 
alimentação, ou mesmo algumas atividades complementares à indústria com baixo grau de conteúdo técnico-científico, tais como serviços de reparo e manutenção de baixa complexidade.

A centralização da gestão da produção reflete na concentração de atividades dealto grau de especialização e informatização, ligados às atividades produtivas, tendo uma participação crescente no valor adicionado das mercadorias, reflexo de seu crescente conteúdo técnico-informacional "cristalizado". Assim, definir-se-á uma tipologia distinguindo os serviços de infraestrutura e reprodução urbana (SIRU), e os serviços técnico-informacionais complementares à produção (STIC).

Comparando a tipologia por tipo de demanda, conforme o proposto por Browning e Singelman (1978), anteriormente explicitada, os SIRU abrangeriam os serviços sociais, pessoais, e parte dos serviços distributivos e produtivos de menor conteúdo técnico-científico, como o setor de transportes, no caso dos serviços distributivos, e serviços de reparo e manutenção de menor complexidade, no caso dos serviços produtivos. Já os STIC abrangeriam a maior parte dos serviços produtivos e distributivos.

Vale destacar que ainda que as regiões de maior centralidade concentrem os STIC, elas também terão SIRU bastante desenvolvidos, inclusive com níveis técnicoinformacionaismaiores do que a média destas atividades, além de um maior nível de diversificação, fruto de uma alta renda urbana.

Os SIRU apresentam estruturas menos verticalizadas com relação à rede urbana, ou mais horizontalizadas, ou seja sua distribuição apresenta centralidades menores e uma distribuição bastante dispersa. Os STIC são relativamente mais verticalizados com relação à rede urbana, apresentando centralidades mais robustas, bem como uma distribuição mais restrita a espaços de maior centralidade.

Esta distribuição reflete, assim, suas funcionalidades no contexto da estruturação da divisão técnico-espacial do trabalho. Os STIC se concentram, pois se relacionam à gestão do território, dependendo de contextos espaciais específicos, tais como oferta de mão-de-obra especializada, ambientes de transbordamento tecnológico, denotando sua alta seletividade espacial. Os SIRU relacionam-se às atividades que viabilizam a fixação e reprodução das atividades rotineiras realizadas no âmbito local, como serviços de educação, saúde, coleta de lixo, alimentação, etc., além das articulações espaciais mais tradicionais, tais como serviços de transporte de cargas. Estas atividades são responsáveis ainda por uma importante funcionalidade, a acomodação de mão-de-obra excedente. Os STIC, por outro lado, têm funções relativas às articulações local-globais: a)telecomunicação e transmissão de informações: favorecendo a comunicação e generalização de informações codificadas, "standardizadas"; b)difusão tecnológica: permitindo a integração e produção da tecnologia em diversas escalas, e a integração da atividade de produção tecnológica às 
atividades produtivas em geral; c)articulação institucional local: possibilitando o aproveitamento dos chamados "ativos relacionais" locais; d)monitoramento da produtividade: a generalização do uso de uma série indicadores de produtividade e rentabilidade permite a tomada de decisões de investimento em um ambiente global; e)diminuição de incertezas espaciais: permite a manutenção de gigantescas estruturas produtivas transnacionais, baseado, sobretudo, em serviços financeiros e securitários; f)inovações tecnológicas: a produção tecnológica e sobretudo a manutenção de ambientes inovativos passa a ser pré-condição de inserção consistente na dinâmica econômica globalizada.

Cabe destacar que apesar do conteúdo técnico-científico aumentar com maior velocidade dentre os STIC, os SIRU também são atingidos pelos transbordamentos tecnológicos dos STIC, aumentando também seu conteúdo técnico-científico, podendo até mesmo apresentar concentrações do ponto de vista qualitativo, ou seja, mesmos os SIRU das localidades de maior centralidade terão maior nível técnico-científico, passando mesmo a ser pré-condição à fixação de mão-de-obra com alto grau de especialização. Assim apesar de diferentes tipos de serviços apresentarem dinâmicas específicas, estes se inserem em uma dinâmica produtiva mais ampla, ainda que cada qual com sua funcionalidade específica.

Buscando analisar a organização espacial das atividades terciárias no Brasil, com vistas para a distribuição espacial do setor terciário brasileiro, utilizou-se o QuocienteLocacional Ajustado (QLA) da massa salarial destas atividades distribuídas por municípios e ramos de atividade, em consonância com a tipologia de Browning e Silgelman (1978). No próximo item será exposta a metodologia utilizada para tal.

\section{3- METODOLOGIA}

\subsection{Quociente Locacional Ajustado (QLA)}

O QLA, como o próprio nome já diz, é uma variação do Quociente Locacional (QL), que procura comparar duas estruturas setoriais-espaciais, buscando ajustar os desvios esperados, relativos a estruturas setoriais muito heterogêneas, que caracterizam a rede de municípios brasileiros. Para isso, ele compara duas estruturas econômicas, sendo que no numerador tem-se a economia em estudo e no denominador uma economia de referência. A fórmula de cálculo é a seguinte: 


\section{$\mathrm{QL}=\underline{\mathrm{P}_{\mathrm{i}} / \mathbf{P}_{\mathbf{i}}}(\mathbf{1})$ \\ $\mathrm{P}_{\mathrm{br}} / \mathrm{P}_{\mathrm{br}}$}

Onde: $\mathrm{P}_{\mathrm{j}}^{\mathrm{i}}$ é o valor relativo a um setor i no município j;

Pj é o valor relativo ao município j;

$\mathrm{P}_{\text {bh }}^{\mathrm{i}}$ é o valor relativo ao setor i no Brasil como um todo;

$\mathrm{P}_{\text {bh }}$ é o valor total no Brasil como um todo.

\subsection{Centro Médio Ponderado (CMP)}

O Centro Médio Ponderado (CMP), representa o centro gravitacional de um conjunto de pontos, tendo em vista a frequência e intensidade destes pontos. Assim, a partir desta distribuição dada pelas coordenas Latitude/Longitude de cada ponto, bem como um valor que sirva de peso, em nosso caso os QLA`s, encontrase o ponto em que estas grandezas se equilibram. Daí tem-se:

$$
\mathbf{X}_{\mathbf{w}}=\frac{\sum \mathbf{w}_{\mathbf{i}} \underline{\mathbf{X}}_{\mathbf{i}}}{\sum \mathbf{w}_{\mathbf{i}}} \quad \mathbf{Y}_{w}=\frac{\sum \mathbf{w}_{\mathbf{i}} \underline{\mathbf{X}}_{\mathbf{i}}}{\sum \mathbf{w}_{\mathbf{i}}}
$$

Onde: wi é o peso relativo ao ponto xi, yi;

xi é a longitude do ponto xi, yi;

yi é a latitude do ponto xi, yi.

A localização do Centro Médio Ponderado é afetada pela localização de cada ponto, bem como de cada peso, de forma que pontos com localizações extremas ou com pesosaltos atraem para si o CMP.

\section{4 - DISTRIBUIÇÃO E EVOLUÇÃO ESPACIAL DAS ATIVIDADES TERCIÁRIAS NO BRASIL}

Desta forma, por meio do QLA relativo às atividades terciárias dos municípiosbrasileiros, nos anos de 1991 e 2000, é possível analisar a distribuição espacial destas atividades, bem como sua evolução no período. Essa análise será feita tendo como base a tipologia de Browning e Singelman (1978), buscando relacionar sua distribuição a sua funcionalidade.

\subsection{A distribuição dos serviços produtivos}

Analisando a distribuição dos serviços produtivos por meio do QLA, o quepercebemos é que este, que é o tipo de serviço que concentra em grande medida os serviços de maior conteúdo técnico-científico, grande 
parte do que nós denominamos STIC, apresenta uma distribuição bastante restrita a localidades de maior centralidade,

como será explicitado adiante.

Na Tabela 1 é apresentado o resultado dos dez melhores colocados, para os anosde 1991 e 2000, com relação ao QLA dos Serviços Produtivos. O que percebemos é que dentre os dez mais bem colocados oito são núcleos metropolitanos em 1991 e sete em 2000, os demais são municípios sobre influência direta de metrópoles. Pegando apenas os que apresentam resultado acima da unidade: em ambos os casos (1991 e 2000$)$ os mesmos cinco municípios, núcleo das principais metrópoles da região centro-sul, a saber: São Paulo, Rio de Janeiro, Belo Horizonte, Curitiba e Porto Alegre.

Tabela 1. Dez Maiores Quociente Locacional Ajustado de Municipios Brasileiros segundo o Tipo de Serviço: 1991-2000

\begin{tabular}{|c|c|c|c|}
\hline \multicolumn{2}{|l|}{1991} & \multicolumn{2}{|c|}{2000} \\
\hline Municipios & QLA & Municipios & QLA \\
\hline \multicolumn{4}{|c|}{ Servicos Produtivos } \\
\hline SAO PAULO & 1.33 & SAO PAULO & 1.51 \\
\hline PORTO ALEGRE & 1.16 & RIO DE JANEIRO & 1.27 \\
\hline RIO DE JANEIRO & 1.15 & BELO HORIZONTE & 1.19 \\
\hline CURITIBA & 1.15 & CURITIBA & 1.16 \\
\hline BELO HORIZONTE & 1.10 & PORTO ALEGRE & 1.14 \\
\hline SANTOS & 0.89 & BRASIIA & 0.88 \\
\hline SALVADOR & 0.84 & SALVADOR & 0.79 \\
\hline CAMPINAS & 0.78 & CAMPNAS & 0.74 \\
\hline BRASIIIA & 0.68 & NIIEROI & 0.74 \\
\hline FORTALEZA & 0.66 & OSASCO & 0.70 \\
\hline \multicolumn{4}{|c|}{ Serviços Distributivos } \\
\hline SAO PAULO & 0.94 & SAO PAULO & 0.96 \\
\hline CURITIBA & 0.87 & CURITIBA & 0.86 \\
\hline BELEM & 0.85 & GOIANIA & 0.85 \\
\hline MANAUS & 0.85 & CAMPINAS & 0.84 \\
\hline RIO DE JANEIRO & 0.83 & GUARULHOS & 0.84 \\
\hline FORTALEZA & 0.83 & RIO DE JANEIRO & 0.83 \\
\hline BELO HORIZONTE & 0.80 & SALVADOR & 0.82 \\
\hline SALVADOR & 0.78 & FORTALEZA & 0.82 \\
\hline GOLANIA & 0.78 & BELO HORIZONTE & 0.78 \\
\hline GUARULHOS & 0.78 & BELEM & 0.77 \\
\hline \multicolumn{4}{|c|}{ Servicos Pessoais } \\
\hline NOVA IGUACU & 1.09 & SALVADOR & 1.01 \\
\hline SAO PAULO & 1.07 & RIO DE JANEIRO & 0.95 \\
\hline RIO DE JANEIRO & 0.89 & SAO PAULO & 0.92 \\
\hline SALVADOR & 0.84 & DUQUE DE CAXIAS & 0.88 \\
\hline BELO HORIZONTE & 0.73 & NOVA IGUACU & 0.86 \\
\hline CURITIBA & 0.70 & CURITIBA & 0.83 \\
\hline FORTALEZA & 0.67 & BELO HORIZONTE & 0.82 \\
\hline PORTO ALEGRE & 0.66 & FORTALEZA & 0.81 \\
\hline DUQUE DE CAXIAS & 0.66 & SAO GONCALO & 0.78 \\
\hline BR_ASILIA & 0.64 & MANAUS & 0.76 \\
\hline \multicolumn{4}{|c|}{ Serviços Sociais e/ou de Utilidade Pública } \\
\hline BRASIIIA & 1.76 & BRASIIA & 1.65 \\
\hline RECIFE & 1.16 & PORTO ALEGRE & 1.23 \\
\hline RIO DE JANEIRO & 1.13 & RECIFE & 1.12 \\
\hline NIIEROI & 1.13 & JOAO PESSOA & 1.10 \\
\hline BELO HORIZONTE & 1.11 & BELO HORIZONTE & 1.09 \\
\hline PORTO ALEGRE & 1.11 & RIO DE JANEIRO & 1.04 \\
\hline SALVADOR & 1.07 & MANAUS & 1.03 \\
\hline NATAL & 1.04 & BELEM & 1.03 \\
\hline JOAO PESSOA & 1.04 & NIIEROI & 1.03 \\
\hline BELEM & 0.99 & SALVADOR & 1.02 \\
\hline
\end{tabular}

Ainda de acordo com a Tabela 1, a evolução do QLA entre 1991 e 2000,demonstra um reforço quanto à condição de primeira centralidade no âmbito nacional exercida por São Paulo, passando de um QLA de 1,33 em 
1991 para 1,51 em 2000. O município do Rio de Janeiro ascende da terceira posição para a segunda diferenciando-se das demais metrópoles abaixo e consolidando sua posição de sub-centralidade, passando de 1,15 para 1,27. Belo Horizonte passa de quinto lugar a terceiro, ultrapassando Curitiba e Porto Alegre ao aumentar seu QLA de 1,10 para 1,19. Curitiba apresenta um crescimento tímido, passando de 1,15 para 1,16, e junto com Porto Alegre, que apresenta uma queda em seu QLA passando de 1,16 para 1,14, perdendo posições quanto à concentração de Serviços Produtivos.

Desta forma, entre 1991 e 2000 a estrutura espacial dos Serviços Produtivos setorna mais complexa, passando de uma situação de centralidade mais simples para uma mais complexa, com níveis hierárquicos diversos, e uma estrutura mais concentrada e verticalizada.

A distribuição destas atividades no território brasileiro pode ser observada noMapa 1, obtido através do QLA do setor. Percebe-se um alto grau de concentração, sobretudo na região sudeste, particularmente na Região Metropolitana de São Paulo, interior paulista e demais metrópoles da região. Pode-se perceber ainda que as demais

metrópoles brasileiras aparecem enquanto enclaves com relação ao setor.

O movimento de concentração do setor fica confirmado no Mapa 5, em que aevolução do Centro Médio Ponderado (CMP) dos serviços produtivos entre 1991 e 2000 demonstra um deslocamento em direção a São Paulo.

\subsection{A distribuição dos serviços distributivos}

Tal como os serviços produtivos, os serviços distributivos relacionam-se diretamente ao sistema produtivo, agindo de forma complementar, o que reflete em estruturas mais concentradas, restrita aos contextos produtivos. Tendo em vista estas características relativas aos serviços distributivos, percebemos que estes apresentam uma estrutura mais desconcentrada e dispersa se comparada à estrutura dos serviços produtivos, representando uma malha relativa ao sistema de distribuição no território como um todo, caracterizando a rede de serviços distributivos como uma rede relativamnete horizontalizada, com centralidades pouco concentradas. Apesar de sua distribuição menos concentrada, característica que vem evoluindo, conforme veremos a seguir, as metrópoles em escala nacional e/ou regional continuam tendo papel preponderante em sua estruturação espacial.

Desta forma, conforme podemos observar na Tabela 2, a estrutura menos concentrada dos serviços distributivos reflete em QLA`s relativamente baixos, sendo que nenhum atinge a unidade. Dentre os dez municípios melhor colocados, todos são metropolitanos, seja em escala nacional ou regional, sendo que nove deles são núcleos de metrópole e um faz parte da região metropolitana de São Paulo. Embora o maior QLA seja de São Paulo, destaca-se que, ao contrário dos serviços produtivos, a concentração dos serviços distributivos não se restringe às metrópoles da região centrosul, aparecendo outras metrópoles regionais, tais como Goiânia, Belém, Manaus, Salvador, Fortaleza, etc. Na evolução entre 1991 e 2000, destaca-se a emergência de Goiânia, Campinas e Guarulhos. 
Analisando agora a Figura 1, confirma-se que a distribuição dos serviços distributivos se dá de forma menos concentrada do que os serviços produtivos, o que garante um mercado doméstico integrado, ainda que bastante diferenciado. Embora isso se dê de forma tímida, a figura demonstra um movimento de relativa desconcentração, com o CMP deslocando-se de forma a se afastar do município de São Paulo, utilizado aqui como ponto de referência.

\subsection{A distribuição dos serviços pessoais}

Tantos os serviços pessoais como os serviços sociais, por relacionarem-se a demandas finais, apresentam estruturas relativamente mais desconcentradas, refletindo a própria dispersão da população no território brasileiro. Apesar destes serviços apresentarem uma distribuição mais dispersa com relação aos serviços distributivos, estes apresentam centralidades mais robustas que os mesmos, com destaque para as metrópoles regionais e nacionais, sobretudo a região metropolitana do Rio de Janeiro. Apesar de sua distribuição mais dispersa, os serviços produtivos têm apresentado um movimento de concentração, reflexo do fortalecimento das metrópoles principais, as da região centro-sul, e do consequente aumento da renda urbana de suas regiões. Além disso, o desenvolvimento desses serviços nessas localidades centrais passa a ser mesmo pré-condição à fixação de mão-de-obra com grau elevado de qualificação.

Os QLA`s demonstram sua dispersão através de concentrações relativamente pequenas, com apenas dois resultados acima da unidade em 1991 e um em 2000.Destacam-se metrópoles regionais com bons resultados como Salvador, Manaus, Fortaleza, etc., além da região metropolitana do Rio de Janeiro, em que se destaca o núcleo, município do Rio de janeiro, além de outros três municípios pertencentes à região metropolitana, a saber: Duque de Caxias, Nova Iguaçu e São Gonçalo. Na evolução entre 1991 e 2000, destaca-se a emergência de Salvador, sendo o único QLA a ultrapassar a unidade em 2000. O município do Rio de Janeiro ganha importância frente a uma relativa perda de importância de São Paulo. Além disso tal como já foi mencionado municípios da região metropolitana do Rio de Janeiro ganham importância. Cabe ressaltar ainda, a entrada de Manaus dentre os dez melhores colocados.

A análise do Mapa 3 revela que este setor de serviços pessoais apresenta uma pequena expansão, reforçando pequenas centralidades nas regiões de fronteira de ocupação, tal como nas regiões norte e centrooeste. Isto acontece porque estes serviços são compostos, em sua maioria, por SIRU`s dando base à fixação dessas novas

populações, na expansão da ocupação do território nacional.

Apesar dessa expansão da rede de serviços pessoais, analisando o movimento da concentração destas atividades, o que se observa é um movimento de reforço da concentração da rede analisada como um todo, como pode ser visto no Mapa 7, em que o CMP desloca-se em direção ao município de São Paulo. A explicação para isso passa pela manutenção do desenvolvimento metropolitano, sobretudo aquele relacionado às metrópoles da região centro-sul, e o consequente aumento da renda urbana destes aglomerados, que continuam a aglutinar estes serviços nestas localidades, principalmente através atividades qualitativamente melhores, com um maior nível de valor agregado, impactando sobre a distribuição da massa salarial destas atividades. Mais do 
que isso, estas atividades passam a ser pré-condição à fixação de mão-de-obra com um nível maior de especialização, ponto fundamental do atual desenvolvimento metropolitano.

Figura 1. Brasil: 1991 e 2000. Quociente Locacional Ajustado dos Municípios Brasileiros segundo o Tipo de Serviço.
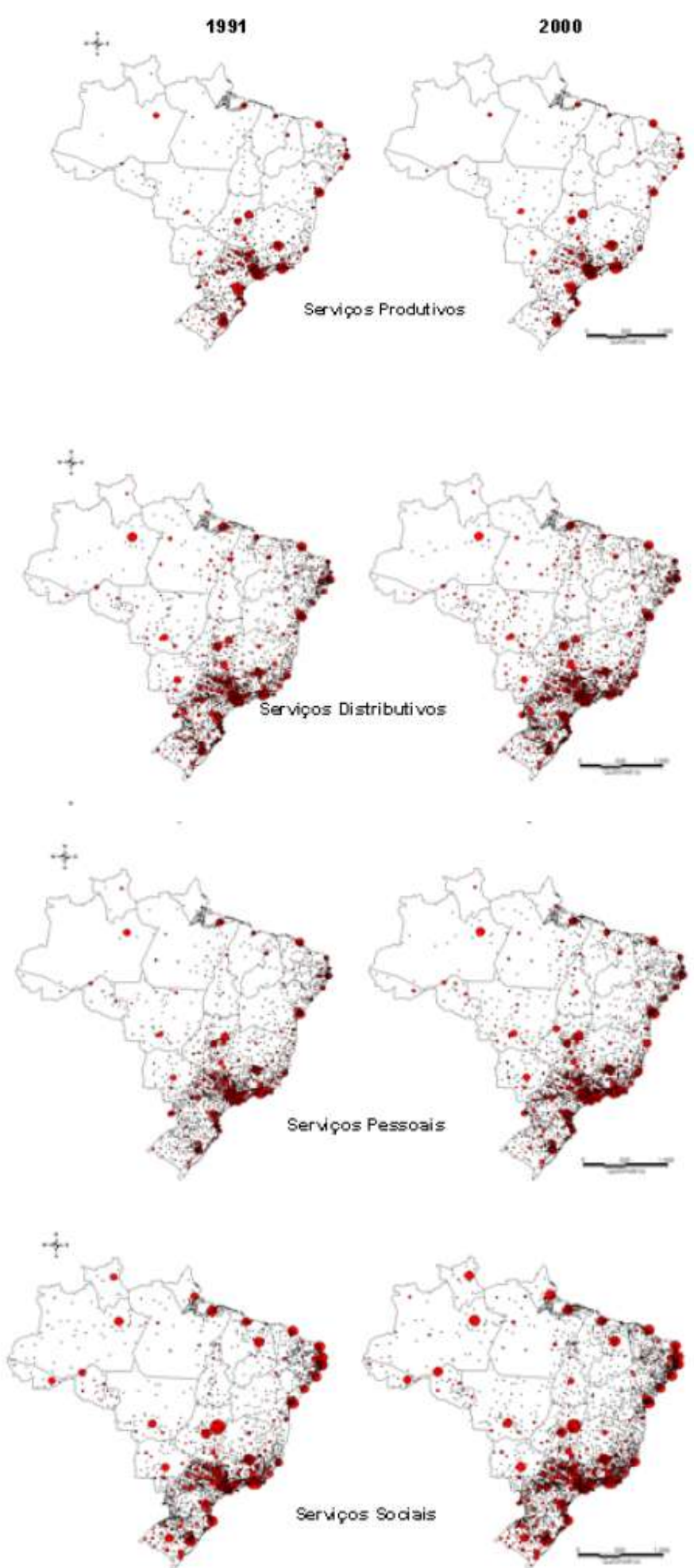
Fonte: IBGE. Censos Demográficos de 1991 e 2000 (microdados), Malha Digital dos Municípios Brasileiros de 1991 e 2000.

Figura 2. Brasil: 1991 e 2000. Pronto Médio Gravitacional do Quociente Locacional Ajustado dos Municípios Brasileiros segundo o Tipo de Serviço

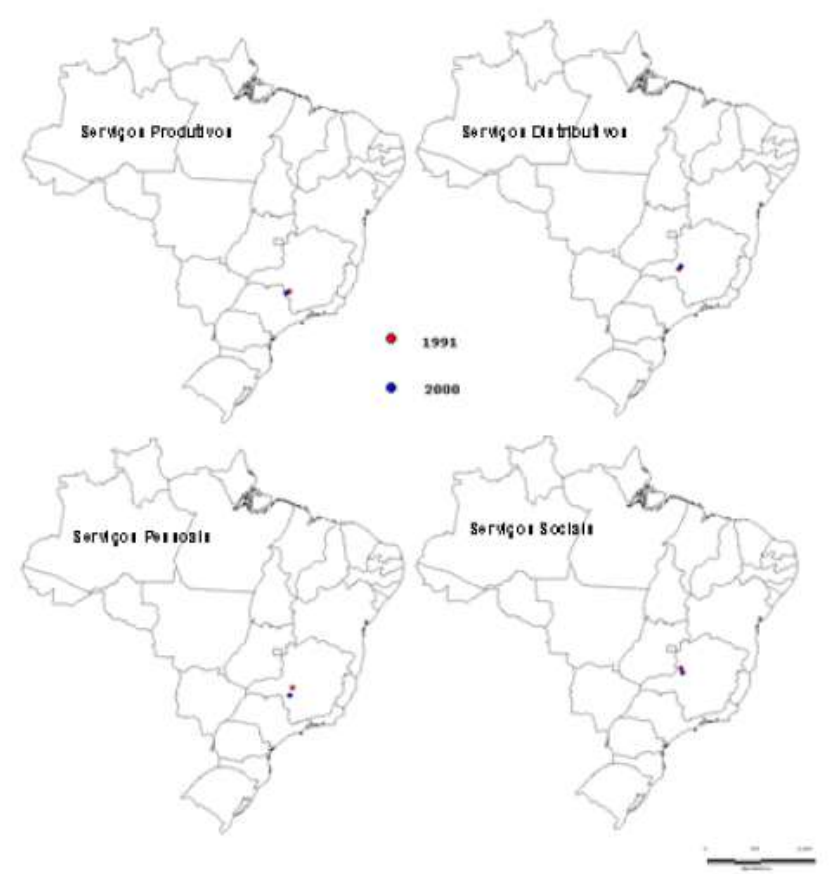

Fonte: IBGE. Censos Demográficos de 1991 e 2000 (microdados), Malha Digital dos Municípios Brasileiros de 1991 e 2000.

\subsection{A distribuição dos serviços sociais e/ou de utilidade pública}

Os serviços sociais e/ou de utilidade pública compostos, em grande medida,pelos relacionados à administração pública, e aos serviços sociais, como educação e saúde, apresentam-se como a rede de maior capilaridade dentre os tipos de serviços aqui analisados. Isso reflete a acentuada dependência de grande parte dos municípios brasileiros com relação a estas atividades, que pontuam o território como um todo. Apesar desse grau de dispersão, estas atividades apresentam um alto grau de verticalidade, de forma que concentram na capital federal e nas capitais estaduais.

Dentre os dez municípios melhores colocados, com relação ao QLA destasatividades, com exceção de Niterói todos eram capitais tanto em 1991, quanto em 2000. Além disso, em 1991 dentre os dez primeiros colocados nove apresentavam um QLA acima da unidade, enquanto em 2000 todos os dez apresentavam QLA`s acima da unidade. Destaque para a liderança de Brasília, que apresenta um pequeno recuo entre 1991 e 2000 , passando de um QLA de 1,76 para 1,65, e para a emergência de Porto Alegre. 
Observa-se ainda a referida capilaridade da rede de serviços sociais e/ou deutilidade pública, com uma distribuição bastante dispersa, porém com várias centralidades espalhadas por todos as unidades da federação, claramente identificáveiscomo suas capitais, denotando a alta concentração das administrações estaduais e da União, além da diferenciação qualitativa da administração pública como um todo.

Ao analisar a Figura 2, tomar-se-á como referência o Distrito Federal e não mais São Paulo, já que este parece ser uma referência melhor no caso específico destas atividades. Desta forma o que se observa é que o CMP se afasta do ponto de referência denotando um movimento de desconcentração destas atividades entre 1991 e 2000,porém esta desconcentração se dá em direção ao sul/sudeste, denotando umdesenvolvimento desigual do setor, com ganho de peso da região centro-sul.

\section{5 - CONCLUSÕES}

A distribuição das atividades terciárias, vista através das tipologias nos permite observar o grau de diferenciação destas atividades, bem como sua relação com a estruturação do território como um todo, sobretudo em um contexto em que o setor terciário se insere no cerne da reestruturação econômica contemporânea, não por ser o núcleo da economia, mas por dar base às articulações espaciais de fluxos, em uma sociedade estruturada crescentemente em redes, onde essas articulações fazem-se cada vez mais necessárias. O caso do Brasil não é diferente, observa-se, em paralelo ao desenvolvimento das metrópoles regionais brasileiras, um movimento em que está sendo formada uma rede terciária capaz de dar base aos fluxos de mercadorias, mão-de-obra, capital, informação, etc., sobretudo nas metrópoles do sudeste, onde se concentram em grande medida as atividades terciárias de maior conteúdo técnicocientífico, sobretudo aquelas ligadas à gestão do território, além de outras atividades que deem base às mesmas.

O movimento de implosão-explosão descrito por Lefebvre (2002) toma forma de sistema, em um processo de separação trabalho intelectual x trabalho manual, em que centraliza-se as funções de planejamento, desenvolvimento, gestão, etc., e dispersa-se as atividades produtivas de acordo com as vantagens comparativas, no contexto de diminuição gradativa dos custos de comunicação e transporte. Esse movimento fica claro no caso brasileiro, pela desconcentração das atividades ligadas à produção, porém com um nível de conteúdo técnico-científico baixo, caso dos serviços de reparo e manutenção, bem como de várias atividades ligadas ao provimento de um suporte territorial básico, em "explosão". Por outro lado as atividades de maior grau de conteúdo técnico-científico demonstram um movimento de "implosão", concentrando nas regiões metropolitanas, sobretudo as da região centro-sul.

Porém deve-se ter em vista que essa relação é "simbiótica", à medida que o trabalho intelectual deve absorver crescentemente o trabalho manual à medida que este se torna seu objeto de análise, dentro de uma economia do aprendizado, das "recalibragens" dos modelos. Aí reside uma possibilidade de ascensão, a universalização de certos serviços urbanos tais como educação e saúde, aliada a políticas de difusão tecnológica, e maior mobilidade espacial, podem possibilitar a ascensão em estruturas sociais, pela inserção no processo inovativo, significando uma janela de oportunidade para países como o Brasil, possibilitando uma inserção 
hierarquicamente superiora na rede urbana mundial, transcendendo a inserção via plataforma produtiva, típica de países em ambientes periféricos.

A formação de uma sociedade baseada no conhecimento e no processo inovativo, nos põe em uma encruzilhada, numa janela de oportunidade por um lado, que é a possibilidade de democratização do acesso ao conhecimento, e assim, o acesso ao mercado de trabalho em condições cada vez mais iguais, ou ao contrário, o "pior dos mundos", a explosão da desigualdade pela falta de acesso ao conhecimento, e amanutenção dos círculos viciosos de pobreza, o que passa em grande medida, por política de educação e outras políticas industriais que possibilitem a inserção nesses meios, como incubadoras, dentre outras iniciativas. Essas observações valem especialmente para países tais como o Brasil, onde essa situação se torna crítica.

Nesse contexto tornam-se particularmente importantes iniciativas de qualificação de mão-de-obra, especialmente iniciativas ligadas à chamada "inclusão digital". Essas iniciativas são essenciais à consolidação de ambientes inovativos, bem como a consolidação de uma estruturação metropolitana, que seja capaz de articular os ambientes locais e globais de forma orgânica.

Assim, no contexto das diversas mudanças na estruturação territorial das atividades econômicas observadas nos últimos anos todas estão entrelaçadas por relações com atividades terciárias, que induzem e são induzidas, que condicionam e são condicionadas, por tal estruturação, o que por si, justifica a pesquisa das relações e do caráter dessas atividades, no novo contexto da sociedades urbano-industriais, conforme buscou-se esclarecer especialmente ao caso brasileiro. O crescimento do setor terciário reflete em grande medida a própria reestruturação da relação capital-trabalho, tendo assim impactos importantes sobre a estrutura do mercado de trabalho, tornando-o mais seletivo, sobretudo com relação ao nível de qualificação.

Não só o mercado de trabalho fica mais seletivo, como a própria distribuição espacial dos fluxos se torna mais seletiva. Isso se comprova observando-se o movimento de esvaziamento de regiões altamente dinâmicas, sobretudo do ponto de vista do terciário, para regiões de menor dinâmica, se comparada com as regiões centrais, porém com crescimento de atividades absorvedoras de mão-de-obra desqualificada ou parcialmente qualificada.

Fica então caracterizada a estruturação das atividades terciárias no território brasileiro, que como se pôde perceber no decorrer do presente trabalho, têm sua distribuição funcionalmente relacionada à estruturação do território como um todo, o que deixa clara a necessidade de se aprofundar no entendimento do setor terciário, buscando entender sua distribuição espacial segundo suas funcionalidade, bem comosua relação com dinâmicas ocupacionais, que busquem esclarecer essa reestruturação da relação capital trabalho e suas relações com uma nova divisão internacional do trabalho, bem como novas inserções ocupacionais que se desenvolvem nesse contexto. O caso brasileiro mostrou-se especialmente esclarecedor dessas dinâmicas territoriais intimamente ligadas às atividades terciárias. 


\section{REFERÊNCIAS BIBLIOGRÁFICAS}

ANDRADE, Mônica Viegas. Setor de Serviços no Brasil: A dualidade revisitada (1981-1990). Belo Horizonte: UFMG/CEDEPLAR, 1994 (Dissertação de Mestrado).

BENKO, Georges. Economia, espaço e globalização: na aurora do século XXI. São Paulo, 1996.

BROWNING, H. C.; SINGELMAN, J. The transformation of the US labour force: the interaction of industry and occupation. Politics and Society, v.8, n 3-4, p. 481-509, 1978;

CARDOSO, Maria F.T.C.; AZEVEDO, Lília M.P. de. Rede de Localidades Centrais: uma tipologia aplicada ao Brasil. Rio de Janeiro: IBGE. Revista Brasileira de Geografia, v.44, n.4, 1982.

CERQUEIRA, Hugo E. A. da Gama; SIMÕES, Rodrigo. Modernização eDiferenciação econômica em Belo Horizonte. Belo Horizonte, 1997.

CHRISTALLER, W. Central places in southern Germany, Jena: Fisher, 1933;

CLARCK, C. Les conditions du progress economic. PressesUniversitaires de France, Paris: 1960;

COHEN, S.; ZYSMAN, J. Manufacturing matters: the myth of the post-industrial economy, New York: Basic Books, 1987;

CORRÊA, Roberto L. Corporação, práticas espaciais e gestão do território. Rio de Janeiro: IBGE. Revista Brasileira de Geografia, v54, n. 3, 1992.

CROCCO, Marco Aurélio; GALINARI, Rangel; SANTOS, Fabiana; LEMOS, Mauro Borges; SIMÕES, Rodrigo. Metodologia de identificação de arranjos produtivos locais potenciais. Belo Horizonte: UFMG/CEDEPLAR, 2003. (Texto para discussão) Disponívelonline: http://www.cedeplar.ufmg.br/pesquisas/td.html.

DINIZ, Clélio Campolina et al; Diretrizes para o Desenvolvimento Econômico de Belo Horizonte. In: Plano Diretor de Belo Horizonte. Belo Horizonte, 1995.

DINIZ, Clélio Campolina; Global-local: Interdependências e Desigualdade ou Notas para uma Política Tecnológica e Industrial Regionalizada no Brasil. Rio de Janeiro: IE/UFRJ, 2000. (Estudos Temáticos). 
DINIZ, Clélio Campolina; Globalização, Escalas Territoriais e Política Tecnológica regionalizada no Brasil. Belo Horizonte: UFMG/CEDEPLAR, 2001. (Texto para discussão) Disponívelonline: http://www.cedeplar.ufmg.br/pesquisas/td.html.

DINIZ, Luís H. Freitas; A distribuição espacial do setor terciário do município de Belo Horizonte - 2002. Belo Horizonte: UFMG/FACE, 2004 (Monografia).

DREIFUSS, René Armand; Transformações: matrizes do século XXI - 2004. Petrópolis: Ed. Vozes, 2004.

FERREIRA, M. S. Rede de cidades em Minas Gerais a partir da realocação da indústria paulista. Nova Economia. Belo Horizonte, Edição Especial, 1996.

FISHER, A.G.B.. A note on tertiary production. The Economic Journal, 1952;

FLORIDA, Richard. Toward learning regions. Futures. Vol 27, Nº5, pp. 527-536. Great Britain: Elsevier Science Ltd, 1995.

FLORIDA, Richard.Cities and Creative Class. Routledge, 2005.

GERSHUNY, J; MILES, I. The new service economy. London: Frances Printer, 1988.

GORZ, André; Los caminhos del paraíso. Barcelona: Laia, 1983.

HILL, T. P..On goods and services. The Review of Income and Wealth, Series 23, p.315-339, 1977;

HABERMAS, Jürgen; Racionalidade e Comunicação. Lisboa: Edições 70, 1996.

HAIG, R.M. Toward an understanding of the metropolis. I. Some speculations regarding the economic basis of urban concentration. QuarterlyJournalofEconomics40, 179-208, 1926.

IANNI , O. A era do globalismo. Rio de Janeiro: Civilização Brasileira, 2001.

KON, A. Atividades terciárias: induzidas ou indutoras do desenvolvimento econômico?.In: FERRAZ, J.C.; CROCCO, M. A. ; ELIAS, L. A. (Ed). Liberalização econômica e desenvolvimento: modelos, políticas e restrições, São Paulo: Futura, p. 180-202, 2003;

LEFEBVRE, Henri; A revolução Urbana. Belo Horizonte: UFMG, 2002. 
LEMOS, Maurício Borges; Espaço e capital: Um estudo sobre a dinâmica centro x periferia. Campinas: UNICAMP/IE, 1988 (Tese de Doutoramento).

LÖSCH, A. The economics of locations. New Haven : Yale University, 1954.

MACEDO, P. B. R. \& SIMÕES, R. Amenidades urbanas e correlação espacial: uma análise interurbana para BH/MG. Revista Brasileira de Economia. 52(4): 525-541, 1998.

MATOS, Ralfo E.; Das grandes divisões do Brasil à idéia do urbano em rede tripartite. In: Matos, Ralfo E. (org). Espacialidades em rede: população, urbanização e migração no Brasil contemporâneo. Belo Horizonte: C/Arte, 2005.

MATTOS, Carlos A. de; Redes Nodos e Cidades: transformação da metrópole latino americana. In: RIBEIRO, Luiz C. Q. (org). Metrópoles: entre a coesão e a fragmentação, a cooperação e o conflito. FASE, Perseu Abramo, observatório das Metrópoles. São Paulo e Rio de Janeiro, 2004.

NORTH, D.C. Teoria da localização e crescimento econômico regional. In:

SCHWARTZMAN, J. ( org. ). Economia regional: textos escolhidos. Belo Horizonte:CEDEPLAR, 1977. P.291314.

NOYELLE, T. J.. The rise of advanced services - some implications for economic development in U.S. cities. APA Journal, 1983;

PANIZZI, W. M..Na urbanização brasileira, ainda o predomínio da metrópole. In: RIBEIRO, A. C. T.; MACHADO, D. P. (Org). Metropolização e rede urbana: perspectivas dos anos 90. Rio de Janeiro: UFRJ/IPPUR, p. 46-53, 1990.

RICHARDSON, H. W. Economia Regional, Teoria da Localização, Estrutura Urbana e Crescimento Regional. Rio de Janeiro: Zahar, 1975.

SANTOS, Milton; A urbanização brasileira. São Paulo: Hucitec, 1993.

SASSEN, S. The global city. Paper prepared for presentation at the conference on cities and space to be held in Belo Horizonte, august, 1991.

SASSEN, Saskia; Ciudades em la economia global: enfoques teoricos y metodologicos. EURE (Santiago), 1998, VOL 24, N. 71. 
SIMÕES, Rodrigo; HERMETO, Ana Maria; AMARAL, Pedro; DINIZ, Luís Henrique F.; Serviços e a Rede Metropolitana. In: Lemos, M. et al. Projeto BH do século XXI. Belo Horizonte: UFMG/CEDEPLAR, 2004. Disponível on line: http://www.cedeplar.ufmg.br/pesquisas/sub_pes_pbh.php.

STORPER, Michael. Territorialização numa Economia Global: possibilidades de desenvolvimento tecnológico, comercial e regional em economias subdesenvolvidas. In: Lavinas, L.; Carleial, L. e Nabuco, M.R. (org). Integração, região e regionalismo. Rio de Janeiro: Bertrand Brasil, 1994.

STORPER, M.. Regional economies as relational assets. In: LEE, R.; WILLS, J. (Ed) Geographies of economies, London: Arnold, 1997.

STORPER, Michael; VENABLES, Anthony J. O Burburinho: a força econômica da cidade. In: DINIZ, Clélio Campolina; Lemos, Mauro Borges. Economia e Território. Belo Horizonte: UFMG, 2005. Von THÜNEN, J. H. The isolated state [1826]. Oxford: Pergamon Press, 1966. 